\section{AMERICAN WORK ON THE ATOMIC BOMB PROJECT}

$\mathbf{J}^{\mathrm{vis}}$

UST as soon as it was discovered that secondary neutrons are liberated in uranium fission to the extent of considerably more than one for each heavy nucleus transformed, and that types of nuclei exist which undergo fission under bombardment with neutrons of all energies, it became a reasonable scientific guess that the attainment of a self-propagating (divergent) nuclear chain-reaction would eventually prove possible. So much was, in fact, commonly known by physicists in the late summer of 1939-and the implications of this knowledge in relation to the likely development of military weapons of extreme power were not altogether unheeded by scientific men whose countries were very obviously slipping helplessly into war. In the United States, also, attempts to arouse official interest in the new possibilities were not entirely without effect. By slow degrees this latter interest quickened, and a few weeks before the Japanese attack on Pearl Harbour, American service chiefs were ready to sanction a greatly intensified effort on the problem. Early in 1942 a full-scale research and development programme was under way and plans for pilot production plants were in hand. Almost exactly three years later, what had appeared in sober estimate so distant was an actuality; the first bomb had not been dropped, but the scientific workers in charge of the project were satisfied that success was wellnigh inevitable, and large production plants were rapidly accumulating the fissile material which it was planned to use.

As is well known, the crucial trial was not staged until mid-July 1945-and it was not until August 6 that the new weapon was used offensively but earlier in the year the scientists' efforts had progressed so far that some of them at least were able to relax a little and look beyond immediate problems of physical research to the impact which the employment of the weapon would be certain to have on the world at large. The heads of the Allied States concerned in the development of the bomb would obviously find it necessary to issue statements setting out briefly what had been done and indicating their policy towards the enemy if he remained unsubmissive; but it was felt that the peoples of the Allied Nations could not be left without further information, and that a popular exposition was needed which would allow them to appreciate the magnitude of the scientific achievement involved and-always within the limits imposed by considerations of security-permit them to look into the future with some guidance in their certain bewilderment.

The American seientists who acted on these conclusions are to be congratulated on the results of their efforts, first in obtaining the support of the military authorities in whose hands the question of security was vested, and secondly on the popular account itself which has been issued by the Government Printing Office in Washington* (and has also been reprinted and published by H.M. Stationery Office in Great Britaint), having been compiled by

* A General Account of the Development of Methods of Using Atomic Energy for Military Purposes under the Auspices of the United States Government, 1940-1945. By Prof. H. D. Smyth Pp. vii +182. (Washington, D.C.: Government Printing Office, 1945.) 35 cents.

$\dagger$ Atomic Energy. (London: H.M. Stationery Office, 1945.) Pp.iv + 144. 2s. $6 d$. net.
Prof. H. D. Smyth, chairman of the Department of Physics of Princeton University. This document, which was authorized for issue in America in August, very soon after the attack on Hiroshima, runs to 182 pages. The author's preface is dated July 1, 1945. The style is reasonably unhurried throughout; the whole thing cannot have been written overnight. It is to be repeated that the foresight which conceived the aim and scale of the report, and which led to its production, is greatly to be commended. In Great Britain we had less in the way of large-scale achievement to report upon, but it will be recalled that we also produced a 'popular' account for issue in August. The American account should be considered in one aspect, at least, in relation to the British one - to the necessarily incomplete but otherwise quite admirable White Paper* published by the Stationery Office. This is said in no spirit of criticism : it reflects merely the statement in Prof. Smyth's preface: "References to British and Canadian work are not intended to be complete since this is written from the point of view of the activities in this country".

The American report is divided into thirteen chapters each with a summary, and there are five appendixes. The first chapter (twenty pages) and the first two appendixes ("Methods of Observing Fast Particles from Nuclear Reactions" and "The Units of Mass, Charge and Energy") provide a background of knowledge of fundamental nuclear physics to supplement the general scientific outlook which the reader of the report is assumed to possess-" "[It] is written for this professional group . . . of engineers and scientific men who can understand such things and who can explain the potentialities of atomic bombs to their fellow citizens". Chapters 2-5 give the administrative history of the project in its various stages, Chapter 6 describes in general terms the research carried out at Chicago in 1942, and Chapters 7 and 8 and 9 to 11 , respectively, trace the development of the production methods used for plutonium 239 and uranium 235, the two fissile materials used for the bombs. The problem of bomb design and assembly is treated separately in Chapter 12, which gives a glimpse of the work of the special laboratory set up at Los Alamos precisely for this purpose. A short final chapter (13) summarizes the whole account-and ends with a call for an acute social consciousness to grapple with the weighty issues which the successful prosecution of the project has raised (Section 6, "Planning for the Future"; Sections 7 and 8, "The Questions before the 'People"). Lastly, Appendixes 3, 4 and 5 are included for the benefit of the semiprofessional nuclear physicist. They give, as examples of the type of fundamental research work carried out in the course of the development programme, brief accounts of an investigation of the delayed neutrons of fission and of the construction and testing of the first self-sustaining chain-reacting pile (which was brought into operation on Docember 2, 1942, at an initial energy output of 0.5 watt)-also a representative list of eighteen titles taken from the index of reports written by the Chicago workers during 1942 .

It will be evident from this brief digest of the contents of the Smyth Report that it cannot fail to make interesting reading. To the general reader the earlier chapters may appeal more than the later ones ; the account of the administrative handling of this vast project will certainly be a revelation to the

- Statements relating to the Atomic Bomb. (London: H.M. Stationery Office, 1945.) $4 d$. net. 
industrialist-it is without question the history of the most complex and extensive industrial project ever brought into co-ordinated operation within a period of little more than two years; it is also, by implication, the story how, in a country of free institutions, under the stress of total war, many hundreds of millions of dollars were expended and many thousands of persons were employed without Congressional sanction or knowledge ("Because of the restrictions of military security there has been no chance for the Congress or the people to debate such questions").

To the scientist, however, the later chapters will probably have the greater appeal. Unless he has been associated with the project he will scarcely have heard of the 'transuranic' elements 93 (neptunium) and 94 (plutonium). To him, Chapters 7 and 8 will be particularly illuminating. $\mathrm{He}_{e}$ will be able to read for the first time a connected account of an altogether amazing achievement in transmutation. A chemical species which does not occur naturally on the earth, and for which the astrophysicist has never produced evidence of occurrence in the stars, has been manufactured on an industrial scale : kilograms--probably hundredweights-of uranium have been transformed, atom by atom, into something strange and new, and, as a by-product, energy has been released at a power which, if expressed in thousands of kilowatts, must certainly involve numbers which are large. He will be interested, too, to know something of the methods by which isotope separation has been achieved for the heaviest of the terrestrial elements-how many kilograms of the rare isotope uranium 235 (natural abundance 0.7 per cent !) have been separated, practically pure, by a bold development of the electromagnetic method, which before the War had been made to yield merely a few micrograms of the separated isotopes of lithium and boron for particular experiments (Chapter 11).

No one can possibly detract from the achievement of the scientists and engineers who brought this amazing project to success in the United States within days which were numbered; but a British reviewer may be pardoned for returning to the subject of the contribution which his colleagues belonging to this country made in the earlier (as to some extent, also, in the later) phases of the work. Let it be said, then, that the Smyth Report recognizes the reality of this contribution. It records the fact that a suggestion was made through the British scientific liaison office in Washington, late in December 1940, that plutonium 239 appeared worthy of serious consideration as material for a bomb (Chapter 3, Section 17), also that the definitive report of the Committee of the National Academy of Sciences dated November 6, 1941, was more conservative than the British report of July 15, 1941 (progressive action being taken on the former only in view of its reinforcement by the latter report; and because of "general urging by a number of physicists"-including Urey and Pegram, who had just returned from a visit to Britain : Chapter 3, Sections 21 and 23). It states quite clearly "The British, particularly J. Chadwick, were convinced that a U235 chain reaction could be achieved. . . . They feared that if the Germans got atomic bombs before the Allies did, the war might be over in a fow weeks. The sense of urgency which Pegram and Urey brought back with them was of great importance" (Chapter 4, Section 47). More could scarcely be expected by way of acknowledgment from an ally and partner (if the reader wishes to learn more of the British effort he should consult the White Paper referred to above). In view of this, it is doubly unfortunate that a charge should be levelled against the "foremost nuclear physicist" of another ally, amounting, at the least, to an accusation of political unwisdom and irresponsibility. It would not appear that the section of the report in question (Chapter 3, Section 2) is factually correct, let alone temperate in utterance. This, however, is but one blemish in a generally admirable and objective presentation.

N. Feather.

\section{PENICILLIN IN THE TREATMENT OF SYPHILIS \\ BY DR. JAMES MARSHALL}

$\mathrm{T}$ is generally agreed that probability of cure 1 in syphilis can only be assumed if, during five years after treatment, there have appeared no signs, clinical or pathological, of relapse or progression. Penicillin was first used in the treatment of syphilis as recently as 1943, and it is now known that the doses originally used were inadequate. We cannot, therefore, begin to estimate the value of penicillin as an agent for the permanent cure of syphilis.

It is possible, however, to describe the remarkable effects of penicillin on the lesions of syphilis at all stages and to give some indication of the short-term therapeutic results. Only the passage of time and careful observation of large numbers of cases treated by various methods will permit the place of penicillin in the treatment of syphilis finally to be evaluated.

Penicillin already bids fair to oust the arsenicals from their position as chief agents in the treatment of syphilis. It has one enormous advantage over arsenic, bismuth and mercury, in that it can be administered in any dosage without fear of dangerous toxic effects. (It must, however, be used cautiously in certain cases of late visceral syphilis for fear of therapeutic shock.) The immediate surface sterilizing action of penicillin in early contagious syphilis is profound and will doubtless have great repercussions in disease control in the future. One can predict that this advantage will, for a time at least, be offset by the fact that penicillin is already showing signs of producing a state of foolhardiness in those treated with it. Some patients with venereal diseases are already treating their conditions in the most light-hearted manner and repeatedly re-expose themselves to infection as soon as they think themselves cured. If penicillin were indeed a 100 per cent cure such people would harm only themselves; but, unfortunately, this is not the case.

\section{Early Syphilis}

The results of past experience allow certain generalizations to be made. It is not possible to cure human or animal syphilis by a single injection of penicillin no matter how high the dosage. Repeated injections are necessary. Intramuscular administration appears to give better results than the intravenous method, whether by multiple injections or by continuous infusion. Injections of penicillin in aqueous solution must be given every three to six hours. Penicillin does not penetrate into the cerebrospinal fluid; in spite of this, it is unnecessary to administer penicillin by the intrathecal route in neurosyphilis. 